\title{
Organic Chemistry à la Genevoise
}

\author{
Clément Mazet, Andreas Zumbuehl, Damien Jeannerat, Jiri Mareda, Alexandre Alexakis, \\ E. Peter Kündig, Jérôme Lacour, and Stefan Matile*
}

\begin{abstract}
This article describes the situation of Department of Organic Chemistry in the year of the 450th anniversary of the University of Geneva.
\end{abstract}

Keywords: Department of Organic Chemistry · University of Geneva

The Department of Organic Chemistry enjoys international recognition for a tradition of excellence in research and teaching. The research activities in the Department focus on the key expertise of the organic chemist, that is the ability to transform matter and to create and study new molecules and supramolecular architectures with relevance in biological, pharmaceutical, medicinal or materials sciences. Unifying 'hard' science with 'artistic' creativity in a unique manner, this distinguishing ability is and will always be needed to maintain our quality of life (more than one third of Swiss exports originate in the fields of chemistry), to tackle the challenges facing our society with regard to energy (e.g. solar energy conversion), environment (e.g. green processing) and public health (e.g. drug resistance), and to realize key scientific discoveries.

The current Department hosts four full professors, two MER (maitre d'enseignement et de recherche, similar to an associate professor), two MA (maître assistant, similar to an assistant professor), and about 70 doctoral and postdoctoral coworkers (Fig. 1). The DCO produces $\sim 60$ publications, awards $\sim 8 \mathrm{PhD}$ degrees and accomplishes $\sim 5$ postdoctoral fellowships per year. Our former students usually find high-level employment without problem. Some prefer to join the leading

\footnotetext{
${ }^{*}$ Correspondence: Prof. S. Matile Department of Organic Chemistry University of Geneva

30 quai Ernest-Ansermet

$\mathrm{CH}-1211$ Geneva 4

Tel.: +4122 3796523

Fax: +4122379 3215

E-mail: stefan.matile@unige.ch
}

regional, national or international industry (Actelion, Addex, Chemspeed, Clariant, DuPont Dow, Firmenich, Givaudan, JT, Lonza, MerckSerono, Nestlé, NovaBiochem, Novartis, OM Pharma, Organon, Roche, Rolex, SICPA, Syngenta, etc.) or join companies elsewhere in Europe or overseas. Others are now successful professors in Switzerland, Australia, Bolivia, Canada, France, Greece, Germany, India, Italy, Japan, Pakistan, Poland, Turkey, UK and USA. Some accounts can be found in this issue.

Memorable molecules made in Geneva can be traced back to amine $\mathbf{1}$ produced in soy sauce and ketchup from tryptophan and glucose following the reaction discovered 1911 by Amé Pictet and Theodor Spengler (Fig. 2). ${ }^{[1]}$ The current generation builds on Charles Jefford's variations of antimalaria natural product artemisinin 2, ${ }^{[2]}$ and on Wolfgang Oppolzer's sultams for the asymmetric synthesis of $s y n$-aldols as in transition state 3. ${ }^{[3]}$ More recent highlights include Paul Müller's Rh-catalysts for the intermolecular $\mathrm{C}-\mathrm{H}$ bond activation to transform substrates as demanding as cyclohexane into the $\mathrm{C}-\mathrm{H}$ aminated product 4, Ulrich Burger's photochemical transformation of alkylpyridiniums into aziridines 5 for the synthesis of glycosidase inhibitors, Kurt Schaffner's photochemistry of cyclohex-3-enone $\mathbf{6}$ or Michael Göbel's artificial kinase 7.[4-7] The main research topics in the current Department are organic synthesis, supramolecular chemistry, chemical biology, NMR spectroscopy and computational chemistry.

Research in the Kündig group focuses on new metal-mediated and metal-catalyzed reactions. Advances in synthetic methods and the understanding of the underlying fundamental processes are intellectually challenging and the resulting insights lead to scientific discovery and useful technological innovation. ${ }^{[8]}$ Highlights emerging form these activities include compounds 8-18 (Fig. 2).

Chiral catalyst and ligand development are key issues in modern synthetic chem-

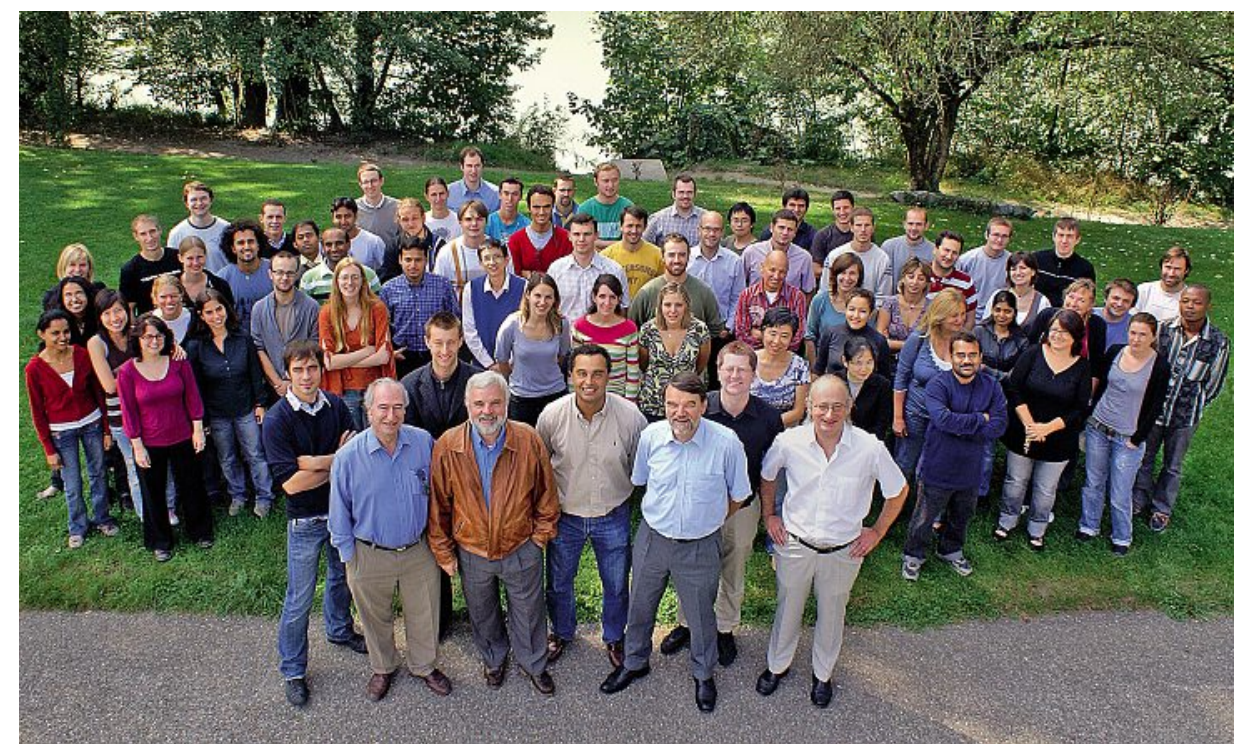

Fig. 1. The Department of Organic Chemistry of the University of Geneva in 2009. In front, from left to right: Clément Mazet, Alexandre Alexakis, Damien Jeannerat, Peter Kündig, Jérôme Lacour, Jiri Mareda, Andreas Zumbuehl and Stefan Matile (Photo: Didier Perret). 
istry and this is a central theme in Peter Kündig's research. Over the past years new chiral iron and ruthenium Lewis acids have been developed. They are characterized by straightforward syntheses, a well-defined structure, and high stability which make easy recycling possible $(\mathrm{Ru})$. They were successfully applied to asymmetric [4+2] and $[3+2]$ cycloaddition reactions giving products in high enantiomeric excess. Crucial in this project was the synthesis and use of new bidentate electron-poor phosphinite ligands. ${ }^{[9]}$

New chiral ligands play central roles in other projects too: Phosphoramidites find application in the desymmetrization of meso-complexes; ${ }^{[10,11]}$ bulky chiral $\mathrm{N}$ heterocyclic carbene ligands led to a breakthrough in the Pd-catalyzed asymmetric intramolecular arylation of amides to give highly enantioenriched 3-disubstituted oxindoles - key building blocks for pharmaceutically active compounds. ${ }^{[12]}$

New chiral diamines, obtained by stripping cinchona alkaloids to a minimum core, proved excellent catalysts for the enantioselective acyl transfer to mesodiols. ${ }^{[13]}$

Arenes and arene $\pi$-complexes form a second central theme in the group. Temporary complexation of an arene to the electrophilic $\mathrm{Cr}(\mathrm{CO})_{3}$ group allows the regioand stereoselective addition of up to three $\mathrm{C}$-fragments across an arene double bond. Subsequent development of asymmetric variants has given rise to a number of efficient routes of access to highly attractive chiral building blocks for organic synthesis. ${ }^{[14]}$ Applications to natural products in the sesquiterpene- and alkaloid field, molecules chosen for their skeletal complexity and biological activity, demonstrate the power of this sequence. ${ }^{[15]}$

The main objective of the Mazet group is to develop readily available chiral catalysts for enantioselective metal-catalyzed reactions. To tackle this challenge we employ state-of-the-art physical-organic chemistry tools to glean insight into the nature of reaction intermediates that govern the reactivity and the selectivity of a given transformation. This strategy allows us to either tune existing catalyst structures to overcome their current limitations or to detract these catalysts from their original purpose by modifying the reaction conditions in order to perform fundamentally different transformations. The later approach was recently applied to the asymmetric isomerization of primary allylic alcohols into the corresponding chiral aldehydes. ${ }^{[16]}$ Successful examples of efficient catalysts for this transformation remain rare and rely solely on the use of chiral rhodium complexes using rather harsh conditions. This is somewhat surprising since the corresponding isomerization of allylic amines to enamines stands out as one of the most accomplished and well-studied reaction in asymmetric catalysis. We have identified highly selective iridium catalysts such as $\mathbf{1 9 / 2 0}$ for the asymmetric isomerization of primary allylic alcohols. Deviating known hydrogenation catalysts from their initial goal towards productive isomerization by adequately tuning the experimental set-up allows this most challenging transformation to take place exclusively and under mild reaction conditions. In addition, preliminary investigations have helped to understand and rationalize crucial features of the reaction mechanism. Implementation of this methodology in the synthesis of biologically active natural substances will be investigated next in our group.

The Alexakis group deals with asymmetric synthesis in a wide sense. The identification of synthetic challenges, in this area, is the driving force in these studies. In addition, efficiency and environmental safety are always kept in mind. Therefore, only catalytic procedures are developed, either with transition metals, or with small organic molecules called organocatalysts. The application of these methodologies to natural products follows.

Over the years, copper was developed for asymmetric conjugate addition on more and more challenging substrates, with various organometallic reagents $(\mathrm{Zn}$, $\mathrm{Al}, \mathrm{Mg}),{ }_{, 17,18]}$ culminating with the unprecedented formation of all-carbon chiral quaternary centres. ${ }^{[19]}$

Copper catalysts were also developed for the asymmetric allylic substitution. [20] Both the nucleophile and the substrates were examined, particularly functionalized ones. Complementary to copper, iridium and palladium were also considered as catalysts, with equal success.

The common feature of all these metalcatalyzed reactions is the chiral ligand. It is the key to reactivity as well as to enantioselectivity. Several families of monodentate ligands have been developed, such as phosphoramidites, aminophosphines (SimplePhos),[21] diaminocarbenes and diamines, including 21-26.

Diamine chemistry was the starting point to new chiral diamine ligands for organolithium reagents, addition reactions, metallation reactions, as well as unprecedented asymmetric metal-halogen exchange. ${ }^{[22]}$ Chiral diamines have also found application as organocatalysts in several reactions, including conjugate additions. [23]

The main research interest of the $L a$ cour group is stereoselective (asymmetric) chemistry in a wide sense and is centred around structural key motifs 27-32. [24-32] Current research programs cover a variety of topics within the areas of enantioselective catalysis $(\mathrm{C}-\mathrm{C}$ and $\mathrm{C}-\mathrm{O}$ bond forming reactions), ${ }^{[24]}$ stereoselective synthesis, ${ }^{[25]}$ asymmetric recognition, ${ }^{[26]}$ surface chemistry,[27] NMR enantiodifferentiation, [28] and these encompass the use of a range of original ionic compounds from enantiopure hexacoordinated phosphate anions (e.g. 27 and 28) to chiral cyclopentadienyle-ruthenium 32,[24] ammonium,, [25] iminium 29, and highly stable carbenium ions $\mathbf{3 0}$ and derivatives. ${ }^{[26,30]}$ In all these studies, the group takes pride in always trying to understand the intricate details of the processes at play and spends time developing evidence for the mechanisms in action. A strong attention is given to ionic situations at play. ${ }^{[31,32]}$ Care is particularly taken to maximize reactivity and selectivity through the selection of chiral counterions.

As a matter of fact, the association of prochiral or chiral ionic species with enantiopure counterions results in the formation of diastereomeric salts. With welldesigned chiral counterions behaving as chiral auxiliaries, the formation of such salts in tightly associated contact ion pairs lead to large chemical and physical differences among the diastereomeric salts and, as a result, favour the selective formation of one. High level of asymmetric recognition between chiral cations and anions is then achieved leading to new and efficient processes of asymmetric detection, resolution, induction and synthesis. This concept has been applied by the group in a variety of fields and in organic, organometallic, metallo-organic and supramolecular chemistry in particular. Good stereoselectivity can be obtained during reactions by the efficient selection of one diastereomerically enriched reactive ion pair containing a prochiral ion and its matched enantiopure counterion; these simple-to-run processes being moreover often operated under green and catalytic conditions.

The general objective in the Matile group is to create supramolecular architectures with interesting functions from scratch for use in molecular optoelectronics (e.g. organic solar cells), ${ }^{[33]}$ diagnostics (e.g. multianalyte sensors $)^{[34]}$ and drug discovery (e.g. multienzyme detectors). ${ }^{[35]}$ To address these challenges, the Geneva approach focuses on lipid bilayers or solid substrates as platforms, rigid-rod molecules as privileged scaffolds, and peptides, naphthalenediimides (NDIs) or perylenediimides (PDIs) as functional modules. Over the years, this has lead to zippers, barrels, slides, helices, stacks and wires that can act as smart, stimuli-responsive photosystems, pores, ion channels, sensors and catalysts.

The introduction of rigid-rod scaffolds was essential for the discovery of artificial $\beta$-barrels 33 (an ubiquitous protein tertiary structure, see below), which in turn pro- 

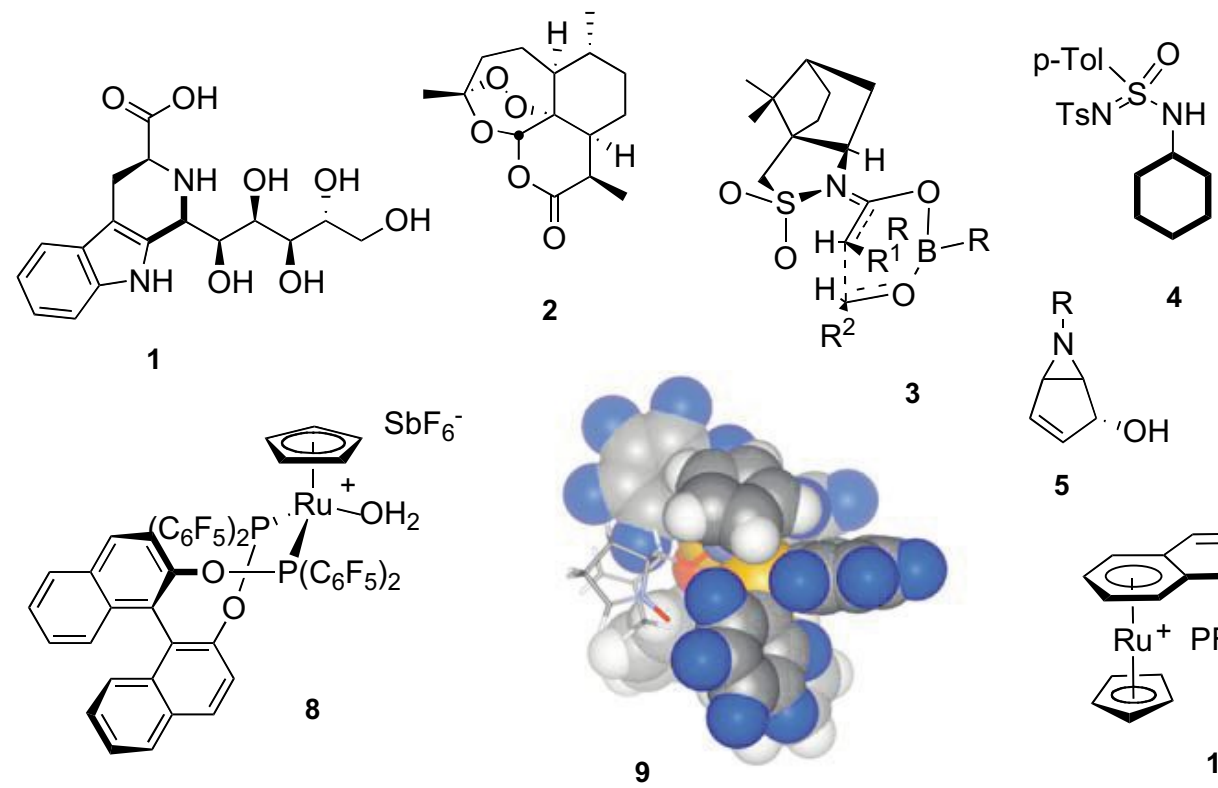<smiles>[R]C1C(=O)CCC2=C1CCC2</smiles>

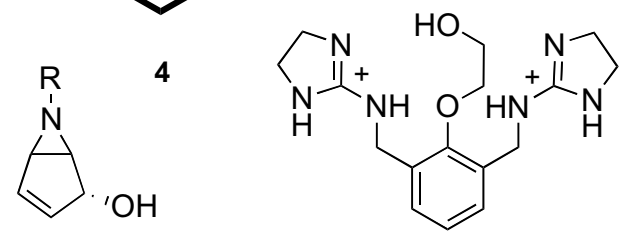

5
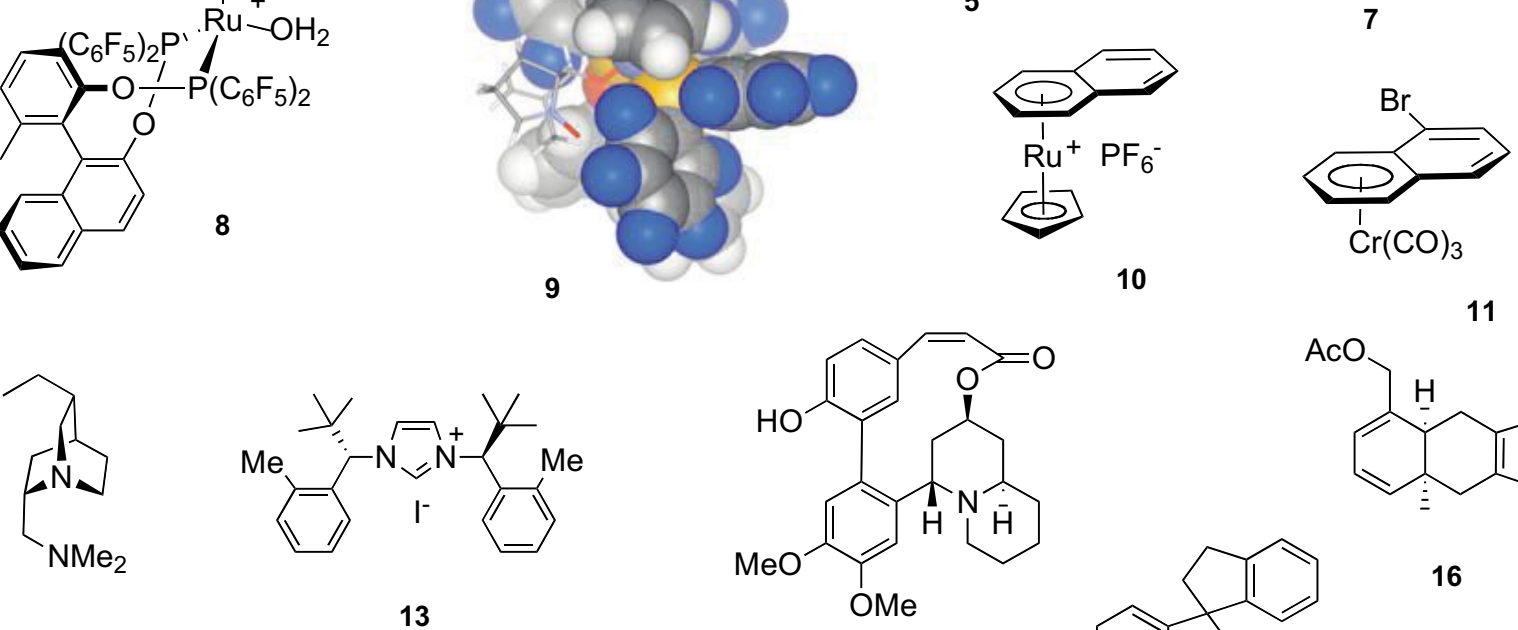

12

14
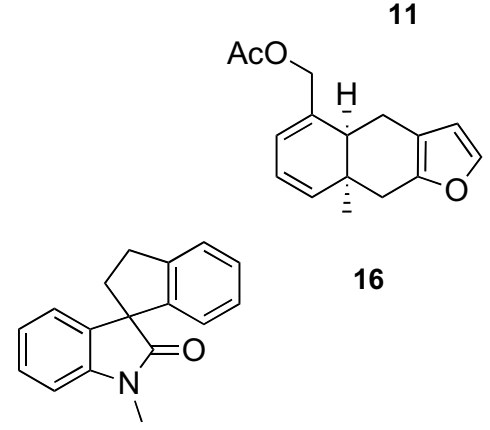

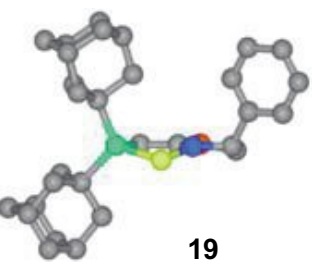

19

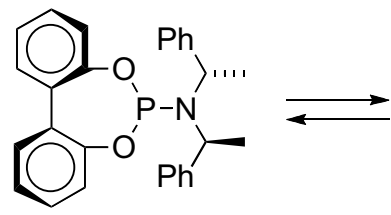

21

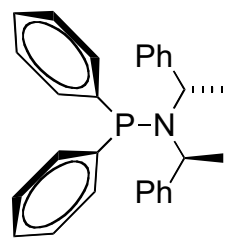

25

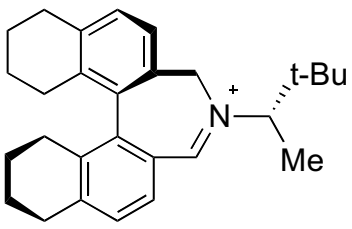

29

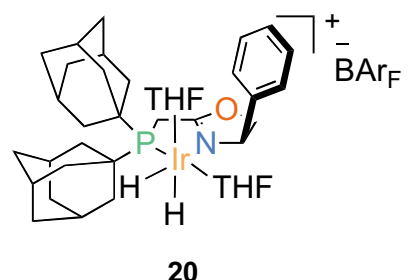

20

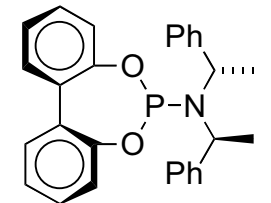

22

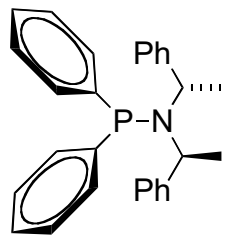

26
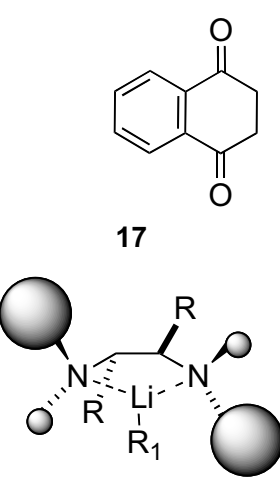

23
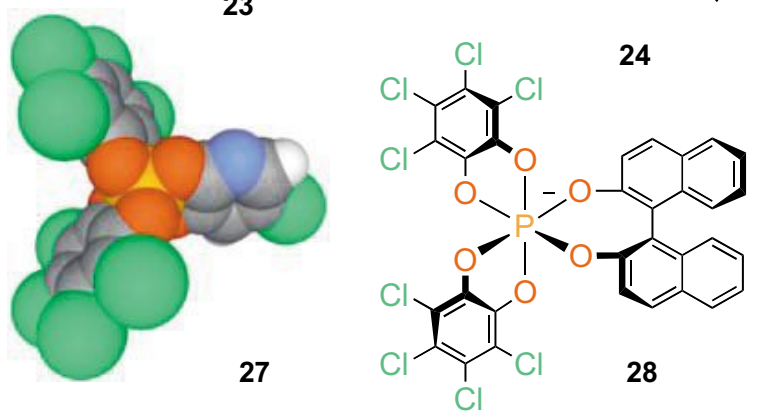

16

15<smiles>COC1=CC=C(C=O)[C@H]2C=CCCC(=O)[C]12</smiles>

18
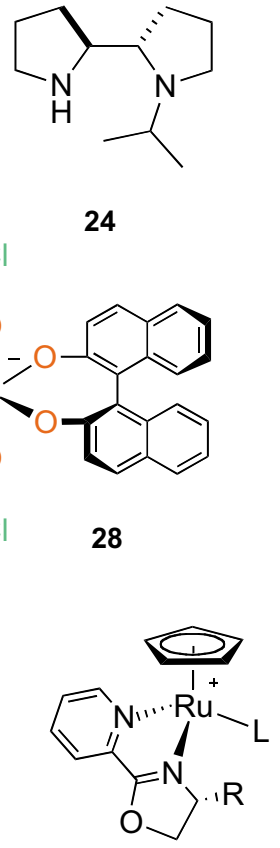

32

Fig. 2. The Hall of Fame: Memorable molecules from past (1-7) and current organic chemistry in Geneva. 


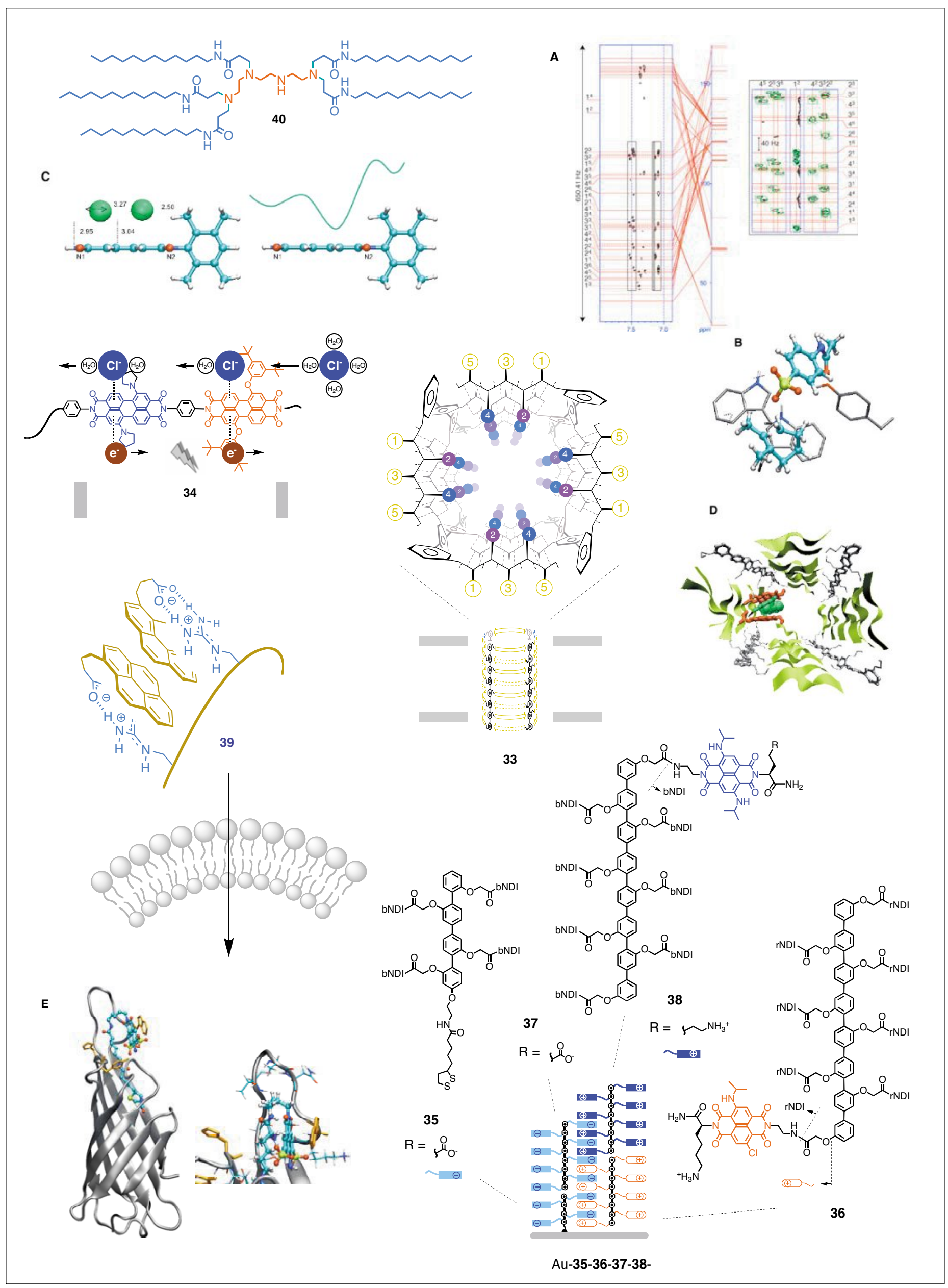

Fig. 2. (cont.) The Hall of Fame: Memorable molecules from past (1-7) and current organic chemistry in Geneva. 
vided access to smart pores that can sense analytes of free choice in samples from supermarket or hospital. Realizing the grand vision of having pores that work like the ones on our tongues or in our noses, this approach has led to numerous sensors (sucrose, lactose, acetate, citrate, lactate, glutamate, phytate, polyphenols, cholesterol). $[34,36]$

Multifunctional photosystems in bilayer membranes such as $\mathbf{3 4}$ were made to combine ion channel and photosynthetic activity. ${ }_{[33,37]}$ Zipper assembly of rods 3538 was introduced to build photosystems with molecular-level control on more solid grounds. ${ }^{[38,39]}$ This is of interest to tackle central challenges in molecular optoelectronics such as the creation supramolecular versions of the bulk $n / p$-heterojunctions (BHJs) of current organic solar, and the installation of rainbow redox cascades as biological photosystems.

Application of the lessons learned to open questions in biology has always been attractive and productive. A recent example is the use of counterions to activate cell-penetrating peptides (CPPs) as polyion-counterion complexes such as $\mathbf{3 9}$ for rapid cytosolic delivery. ${ }^{[40]}$

The Zumbuehl group is interested in the chemical lipidology of nonnatural phospholipids. Lipids are at the heart and beginning of life. Surprisingly though, they were long neglected and seen as a rather uninteresting class of molecules necessary only for building membranes. In recent years, this picture has started to change and the field of lipidomics has already identified thousands of lipids that are involved in any conceivable part of a cell's function. This new field is also providing ample opportunities for organic chemists.

Nature builds the class of phospholipids from a limited set of interchangeable elements. The goal of the Zumbuehl group is to synthesize new, nonnatural lipids such as $\mathbf{4 0}$ by providing additional building blocks. Phospholipids are created bearing chemical handles that cannot be found in nature. These molecules are studied using biophysical techniques and are also tested for their potential in biology and medicine. ${ }^{[41]}$ In particular, the group is interested in new delivery particles as well as medicinal surfaces.

The group of Damien Jeannerat focusses on NMR methodology and its applications to chemical problems. In recent years different methods have been developed to increase the resolution of heteronuclear 2D experiments. Taking advantage of a property of Fourier transform that allows the prediction of the position of signals when drastically reducing the carbon spectral windows, they could take advantage of the increased carbon evolution to resolve signals with very small differences in carbon chemical shifts (Fig. 2A). Different solutions have been developed. Some are sophisticated methods for the specialist to record fully-resolved spectra in the minimal acquisition time. ${ }^{[42]}$ But they also proposed simple solutions applicable by any chemist confronted with overlap problems in HSQC or HMBC spectra. ${ }^{43]}$ Among the applications of HSQC-based experiments one can cite kinetic studies, relaxation and diffusion measurements. ${ }^{[4]}$ During the last few months they developed applications based on NMR titration using HSQC spectra. The demonstration application consists in the determination of the $\mathrm{pKa}$ of a set of six similar molecules in a single fully-automated titration experiment.

Rooted in the area of organic chemistry, the research of the Mareda group is directed towards the relationship between the structure and function of complex supramolecular systems which are studied by quantum chemistry methods (QM) as well as by molecular dynamics (MD) simulations. Applications of computational methods to study the reactive intermediates and mechanisms of organic reactions are also pursued. Central to our interest is the QM modeling of noncovalent interactions in organic and bio-organic contexts.

Among numerous interdepartmental collaborations on reaction mechanisms, computational studies of solvolysis ${ }^{[45]}$ and $a b$ initio investigations of electronic structure of bicyclobutonium ions ${ }^{[46]}$ were vital for undertaking later on the modeling of cation-olefin cyclizations. ${ }^{[47]}$ The mechanism of these cyclizations was studied by QM methods in solution and when catalyzed by antibodies. The modeling shows that the cation- $\pi$ interactions at the catalytic site of the antibody are crucial (Fig. $2 B)$. Anion- $\pi$ interactions and their use for transmembrane transport were simulated focusing on oligonaphthalenediimides (O-NDIs) and their monomeric models (Fig. 2C). ${ }^{[48]}$ Molecular modeling of $\pi-\pi$ interactions were studied in context of artificial functional pores made in the Matile group. ${ }^{[49,50]}$ Particularly attractive were computational simulations of $\pi-\pi$ interactions within rigid-rod $\beta$-barrel architectures, where aromatic electron donor-acceptor interactions between NDI tweezers and dialkoxynaphthalene (DAN) amplifiers can be used for sensing applications (Fig. 2D). [51]

Computational studies of $\pi-\pi$ interactions in natural proteins are also pursued. For example the biotinylated Lucifer Yellow and streptavidin or avidin proteins can develop strong $\pi-\pi$ interactions as revealed by the close contact with $\operatorname{Trp}^{120}$ (Fig. 2E). ${ }^{[52]}$

One key to the success of organic chemistry in Geneva is a fruitful network of collaborations within the Department as well as the School of Chemistry to share not only equipment but also expertise and pleasure. These internal collaborations are naturally complemented by many collaborations on national and international level. Research accomplished in the DCO has been recognized with the $C A S$ Spotlight Recognition (for the most-accessed paper in chemistry and related sciences), most-cited awards in Tetrahedron, Tetrahedron Asymmetry and Bioorg. Med. Chem., top-ten mostaccessed/-cited publications in Acc. Chem. Res., Chem. Soc. Rev., Adv. Synth. Catal., Angew. Chem., Int. Ed., Chem. Commun., ACS Chem. Biol., Org. Biomol. Chem. and Bull. Chem. Soc. Jpn., etc. Members of the Department regularly organize prestigious international conferences (OMCOS 2005, EUCHEMS 1, Budapest 2006, Chirality 2008, EUCHEM Conference on Stereochemistry (Bürgenstock Conference), etc.) and join or chair editorial boards (Chem. Commun., Chimia, Chirality, Org. Biomol. Chem., Helv. Chim. Acta, Tetrahedron, Tetrahedron Letters, Tetrahedron Asymmetry, etc.) and societies (Swiss Acad. Sci., Swiss Chem. Soc.). Whereas research topics in the Department will evolve with the departure of current faculty members and the arrival of new ones, the ambitious longstanding objective, arguably implemented by Charles Jefford and vigorously developed by Wolfgang Oppolzer, to meet highest international standards of excellence will remain unchanged.

We thank the University of Geneva, the Swiss National Science Foundation, the State Secretariat for Education and Research (COST office), the Roche Research Foundation, BASF, DSM, Novartis, PPGSIPSY, Rhodia, the Société Académique de Genève, the Fonds X. Givaudan, the Fonds F. Firmenich and P. Chuit and the Fonds M. Birkigt for constant and generous financial support of this research.

Received: October 10, 2009

[1] A. Pictet, T. Spengler, Chem. Ber. 1911, 44, 2030.

[2] C. W. Jefford, Drug Discov. Today 2007, 12, 487.

[3] W. Oppolzer, J. Blagg, I. Rodriguez, E. Walther, J. Am. Chem. Soc. 1990, 112, 2167.

[4] C. Liang, F. Robert-Peillard, C. Fruit, P. Müller, R. H. Dodd, P. Dauban, Angew. Chem., Int. Ed. 2006, 45,4641 .

[5] E. A. Acar, F. Glarner, U. Burger, Helv. Chim. Acta 1998, 81, 1095.

[6] B. Winter, K. Schaffner, J. Am. Chem. Soc. 1976, 98, 2022.

[7] M.-S. Muche, M. W. Göbel, Angew. Chem., Int. Ed. 1996, 35, 2126.

[8] P. Kündig, Science 2006, 314, 430.

[9] J. Rickerby, M. Vallet, G. Bernardinelli, F. Viton, E. P. Kündig, Chem. Eur. J. 2007, 13, 3354.

[10] E. P. Kündig, P. D. Chaudhuri, D. House, G. Bernardinelli, Angew. Chem., Int. Ed. 2006, 45, 1092.

[11] A. Mercier, W. C. Yeo, J. Chou, P. D. Chaudhuri, G. Bernardinelli, E. P. Kündig, Chem. Commun. 2009, 5227. 
[12] Y. Jia, J. M. Hillgren, E. L. Watson, S. P. Marsden, E. P. Kündig, Chem. Commun. 2008, 4040.

[13] E. P. Kündig, A. Enriquez Garcia, T. Lomberget, P. Perez Garcia, P. Romanens, Chem. Commun. 2008, 3519.

[14] E. P. Kündig, A. Bellido, K. P. Kaliappan, A. Pape, S. Radix, Org. Biomol. Chem. 2006, 4, 342.

[15] E. P. Kündig, M. S. Laxmisha, R. Cannas, S. Tchertchian, R. Liu, Helv. Chim. Acta 2005, 88, 1063.

[16] L. Mantilli, D. Gérard, S. Torche, C. Besnard, C. Mazet, Angew. Chem., Int. Ed. 2009, 48, 5143.

[17] A. Alexakis, C. Benhaim, Eur. J. Org. 2002, 3221.

[18] A. Alexakis, J. E. Backvall, N. Krause, O. Pamies, M. Dieguez, Chem. Rev. 2008, 108, 2796.

[19] C. Hawner, K. Li, V. Cirriez, A. Alexakis, Angew. Chem., Int. Ed. 2008, 47, 9122.

[20] C. Falciola, A. Alexakis, Eur. J. Org. Chem. 2008, 3765.

[21] L. Palais, I. S. Mikhel, C. Bournaud, L. Micouin, C. A. Falciola, M. Vuagnoux-d'Augustin, S Rosset, G. Bernardinelli, A. Alexakis, Angew. Chem., Int. Ed. 2007, 46, 7606.

[22] Q. Perron, A. Alexakis, Tetrahedron Asymmetry 2007, 18, 2503.

[23] S. Sulzer-Mossé, A. Alexakis, Chem. Commun. 2007, 3123.

[24] S. Constant, S. Tortoioli, J. Müller, D. Linder, F. Buron, J. Lacour, Angew. Chem., Int. Ed. 2007, 46, 8979.

[25] M.-H. Gonçalves-Farbos, L. Vial, J. Lacour, Chem. Commun. 2008, 829.

[26] R. Zalubovskis, A. Bouet, E. Fjellander, S. Constant, D. Linder, A. Fischer, J. Lacour, T.
Privalov, C. Moberg, J. Am. Chem. Soc. 2008, 130, 1845.

[27] B. Baisch, D. Raffa, U. Jung, O. M. Magnussen, C. Nicolas, J. Lacour, J. Kubitschke, R. Herges, J. Am. Chem. Soc. 2009, 131, 442.

[28] H. S. Chow, E. C. Constable, R. Frantz, C. E. Housecroft, J. Lacour, M. Neuburger, D. Rappoport, S. Schaffner, New. J. Chem. 2009, 33, 376.

[29] J. Lacour, D. Linder, Chem. Rec. 2007, 7, 275.

[30] P. Mobian, C. Nicolas, E. Francotte, T. Bürgi, J. Lacour, J. Am. Chem. Soc. 2008, 130, 6507.

[31] J. Lacour, D. Linder, Science 2007, 317, 462.

[32] J. Lacour, V. Hebbe-Viton, Chem. Soc. Rev. 2003, 32, 373.

[33] S. Bhosale, A. L. Sisson, P. Talukdar, A. Fürstenberg, N. Banerji, E. Vauthey, G. Bollot, J. Mareda, C. Röger, F. Würthner, N. Sakai, S. Matile, Science 2006, 313, 84.

[34] S. Litvinchuk, H. Tanaka, T. Miyatake, D. Pasini, T. Tanaka, G. Bollot, J. Mareda, S. Matile, Nat. Mater. 2007, 6, 576.

[35] G. Das, P. Talukdar, S. Matile, Science 2002, 298, 1600.

[36] S. M. Butterfield, T. Miyatake, S. Matile, Angew. Chem., Int. Ed. 2009, 48, 325.

[37] A. Perez-Velasco, V. Gorteau, S. Matile, Angew. Chem., Int. Ed. 2008, 47, 921.

[38] N. Sakai, A. L. Sisson, T. Bürgi, S. Matile, J. Am. Chem. Soc. 2007, 129, 15758.

[39] R. Bhosale, A. Perez-Velasco, V. Ravikumar, R. S. K. Kishore, O. Kel, A. Gomez-Casado, P. Jonkheijm, J. Huskens, P. Maroni, M. Borkovec, T. Sawada, E. Vauthey, N. Sakai, S. Matile, Angew. Chem., Int. Ed. 2009, 48, 6461.

[40] T. Takeuchi, M. Kosuge, A. Tadokoro, Y. Sugiura, M. Nishi, M. Kawata, N. Sakai, S. Matile, S. Futaki, ACS Chem. Biol. 2006, 1, 299.
[41] A. Akinc, A. Zumbuehl, M. Goldberg, E. S. Leshchiner, V. Busini, S. A. Bacallado, N. Hossain, R. Alvarez, A. Borodovsky, T. Borland, R. Constien, A. de Fougerolles, J. R. Dorkin, K. N. Jayaprakash, M. Jayaraman, M. John, V. Koteliansky, M. Manoharan, L. Nechev, J. Qin, T. Racie, D. Raitcheva, K. G. Rajeev, D. W.Y. Sah, J. Soutschek, I. Toudjarska, H.-P. Vornlocher, T. S. Zimmermann, R. Langer, D. G. Anderson, Nat. Biotechnol. 2008, 26, 561.

[42] D. Jeannerat, J. Magn. Reson. 2007, 186, 112.

[43] B. Vitorge, S. Bieri, M. M. Humam, P. Christen, K. Hostettmann, O. Muñoz, S. Loss, D. Jeannerat, Chem. Commun. 2009, 950.

[44] G. Gasparini, B. Vitorge, P. Scrimin, D. Jeannerat, L. J. Prins, Chem. Commun. 2008, 3034.

[45] P. Müller, J. Mareda, in 'Cage Hydrocarbons', Ed. G. A. Olah, Wiley, 1990, p. 189.

[46] J.-F. Fuchs, J. Mareda, J. Mol. Struct. Theochem. 2005, 718, 93.

[47] C. C. J. Fouillet, J. Mareda, J. Mol. Struct. Theochem 2002, 589-590, 7.

[48] J. Mareda, S. Matile, Chem. Eur. J. 2009, 15, 28.

[49] N. Sakai, J. Mareda, S. Matile, Acc. Chem. Res. 2008, 41, 1354.

[50] S. Hagihara, L. Gremaud, G. Bollot, J. Mareda, S. Matile, J. Am. Chem. Soc. 2008, 130, 4347.

[51] H. Tanaka, G. Bollot, J. Mareda, S. Litvinchuk, D.-H. Tran, N. Sakai, S. Matile, Org. Biomol. Chem. 2007, 5, 1369.

[52] A. Fürstenberg, O. Kel, J. Gradinaru, T. R. Ward, D. Emery, G. Bollot, J. Mareda, E Vauthey, ChemPhysChem 2009, 10, 1517. 